Revista Iberoamericana, Vol. LXVIII, Núm. 200, Julio-Septiembre 2002, 559-562

\title{
EDITORIAL \\ EL INSTITUTO INTERNACIONAL DE LITERATURA IBEROAMERICANA Y SUS PUBLICACIONES
}

Fundado y organizado en 1938, por un grupo de entusiastas y desinteresados obreros del Espíritu, el Instituto Internacional de Literatura Iberoamericana ha venido desde entonces impulsando sin cesar sus varias publicaciones, dedicadas todas única y exclusivamente al estudio y a la difusión de las letras iberoamericanas, y al noble ideal de acercamiento cultural entre las naciones y los pueblos del Hemisferio Occidental.

Componen el Instituto muchos letrados y catedráticos de literatura iberoamericana, jóvenes recientemente iniciados unos, y los más hombres que han luchado ya por años y años, y contra viento y marea, en defensa de esa literatura unas veces, y otras por estudiarla sistemáticamente y por difundirla y hacer que se le asigne el puesto que merece en el mundo literario. Los socios del Instituto, oriundos de todos los países americanos del Norte y del Sur, son hombres sinceros e independientes, que pertenecen a diversas escuelas filosóficas y religiosas, políticas y literarias, y que sólo tienen en común su fe en los destinos del Hemisferio Occidental, y su deseo viril de servir a la Causa de su Cultura en formación.

Apoyan al Instituto algunas universidades y bibliotecas, patrocinando sus publicaciones, pero sin ejercer sobre él ningún dominio, antes bien respetando discreta y generosamente su integridad moral, su independencia y su imparcialidad y honradez intelectuales.

Así, y en un ambiente más o menos apacible — que no está al margen de la vida-, trabajan los socios del Instituto, venciendo obstáculos y distancias, y luchando contra la inercia que caracteriza a las grandes masas populares norte y sudamericanas en las cosas relacionadas con la Cultura, decididos como están a sacar adelante su generosa empresa y a realizar su ensueño continental. Dos veces ya —en las ciudades de México (1938) y Los Ángeles (1940) — se han reunido en brillantes y memorables Congresos los socios del Instituto Internacional de Literatura Iberoamericana, y por tercera vez se reunirán en la de Nueva Orleans, el mes de diciembre de este año. Empero, son las publicaciones del Instituto lo que en realidad indica su existencia y su vitalidad, y lo que de ellas va adquiriendo valor histórico de indiscutible e indiscutida permanencia. 


\section{Las Memorias de los Congresos}

Se han publicado ya dos Memorias, la del Primer Congreso, reunido en México, y la del Segundo, reunido en Los Angeles.

Bella y cuidadosamente impresas bajo la dirección técnica de don Francisco Monterde, las dos Memorias son dos tomos voluminosos que contienen no sólo los documentos relacionados con la fundación, la organización y la reorganización del Instituto y sus varias Comisiones, y los discursos pronunciados en los dos Congresos, sino los estudios presentados a su consideración, obra esmerada de especialistas, encarnación de esfuerzos de erudición y de crítica literarias, que no deben faltar en las bibliotecas públicas y universitarias del Hemisferio Occidental.

Los estudios publicados en las Memorias, de gran diversidad y algunos de muchísimo valor, lo son ora de lingüística iberoamericana, ora de crítica literaria, de historiografía, de bibliografía, y presentan o aclaran puntos desconocidos u oscuros en los campos de la novelística, la poesía y la sociología iberoamericanas.

\section{La Biblioteca de Clásicos de América}

Saben bien los catedráticos de literatura iberoamericana —así del Norte como del Sur - que de cuantos obstáculos se les presentan en su carrera el mayor es la falta, a veces absoluta, de materiales adecuados y completos para adelantar la enseñanza en forma sería, sistemática y constructiva. Aun las obras de los mayores escritores iberoamericanos están fuera del alcance de los grupos estudiantiles: unas se hallan dispersas en revistas y periódicos locales, otras en libros de adquisición difícil o imposible, ya por estar agotadas sus ediciones, ya por andar tan mal organizado el mercado de libros iberoamericanos. Además, escasean las ediciones críticas de libros y de autores, y en muchos casos no existen trabajos biográficos y bibliográficos dignos del nombre. Al enfrentarse con sus alumnos, el catedrático honrado, por grande que sea su versación en la materia, tiene que hacerse siempre estas preguntas angustiadas: ¿qué libros, qué textos, podrán estudiar las alumnos si no los hay? ¿Cómo interpretar debidamente a un autor iberoamericano cuyas obras no pueden conseguirse en cantidades suficientes para uso de estudiantes, aunque de cada una de ellas se hallan referencias en las "historias" de la literatura, o en artículos periodísticos que las mencionan o discuten fragmentariamente?

Con la esperanza de salvar tan grave obstáculo para la enseñanza, el Instituto Internacional de Literatura Iberoamericana ha iniciado ya, y se propone realizar ampliamente, su "Biblioteca de Clásicos de América” que constará algún día de cien volúmenes, esmeradamente editados por eruditos y críticos competentes en cada caso, también impresos en forma pulcra, como corresponde a su contenido.

La “Biblioteca de Clásicos de América” aspira a ser completa, amplia y representativa, y ha de constituir no sólo una selección de autores y de obras iberoamericana; sino una historia de la literatura iberoamericana. En cada volumen, la selección literaria del autor irá siempre acompañada de un estudio biográfico y crítico, de notas explicativas y de una bibliografía. Así, cada volumen constituye un curso de estudio sobre el autor. 
El Instituto llama de "clásicos" su biblioteca, no porque se ciña a un criterio literario de índole “académica”, así como así ... Los autores que irán figurando en ella serán los más representativos de todos los países iberoamericanos, es decir, los que, aun perteneciendo a diversas escuelas literarias, han logrado un alto puesto como exploradores de la conciencia de América, y la han enriquecido con nuevos hallazgos psicológicos y estéticos, ora revelando los rasgos esenciales de esa conciencia, ora dándoles vida perdurable a ideas y emociones antes desconocidas, ora expresándolas en estilos que pueden llamarse ejemplares por su originalidad, su fuerza, su pureza, su exquisitez.

De la “Biblioteca de Clásicos de América” circula ya el primer volumen, la Antología poética de González Prada, y está para entrar en circulación el segundo, Prosas y versos de José Asunción Silva, los dos preparados y editados con esmero y pulcritud, e impresos dignamente. Ya en marcha, y acogida con entusiasmo y suma benevolencia por la alta crítica iberoamericana, la “Biblioteca de Clásicos de América” se irá realizando con ritmo acelerado y gracias al esfuerzo de muchos críticos y eruditos, y habrá de ser un monumento comparable a otros de carácter semejante realizados en los más famosos centros culturales del Viejo Mundo.

\section{An Outline History of Spanish American Literature}

Utilísima como guía primaria para la enseñanza de la historia de la literatura iberoamericana es esta obrita, cuidadosamente preparada por cinco de los más jóvenes y entusiastas entre los socios del Instituto, y publicada por la casa F. S. Crofts and Co., de Nueva York.

Como lo indica su título, An Outline History of Spanish American Literature no aspira a ser un tratado verdadero, completo y detallado de la historia — que está por hacer- de la literatura iberoamericana de ayer y de hoy. Por eso es más bien un esquema general, preparado para uso de profesores y alumnos de los colegios y las universidades de los Estados Unidos, instituciones que, en la mayoría de los casos, apenas acaban de darse cuenta de la importancia de esa literatura, y quieren enseñarla sin tener para ello todavía materiales suficientes y adecuados.

Los letrados hispanoamericanos hallarán sin duda “defectuosa” esta guía en algunos de sus aspectos, y sobre todo si, al juzgarla, no consideran el hecho de que no fue preparada para ellos, sino para los no iniciados en materias tan complejas, ni consideran que sus autores se vieron obligados a ocuparse sólo de las obras hispanoamericanas que han sido consagradas ya por el tiempo, por una parte, y por otra, de las que, por ser disponibles, sí pueden estudiarse en los colegios y universidades de los Estados Unidos.

Preparada por los mismos, An Outline History of Spanish American Literature será pronto complementada por una voluminosa Antología que publicará también la casa F. S. Crofts and Co.

\section{La Revista IBEROAmericana}

Recibida con muestras de grande simpatía por todos los que en América se interesan de veras en el estudio de su literatura, la REVISTA IBEROAMERICANA ha venido 
cumpliendo su cometido con singular acierto y desprendimiento. Nuestra Revista es la única dedicada exclusivamente al estudio de las letras iberoamericanas, de cuantas se publican y se han publicado en el mundo. Y sin embargo, con éste han circulado ya nueve números, es decir, nueve tomos que alcanzan más de dos mil páginas, o en otras palabras, más de cien estudios de crítica literaría, más de doscientas reseñas de libros, y algunas bibliografías insuperables.

Se ha dicho que la REVISTA IBEROAMERICANA se ocupa sólo de las letras de siglos pasados. El cargo es injusto y carece de fundamento. Como revista de erudición que no de propaganda de ninguna clase- - es natural que la nuestra se ocupe especialmente de autores y de obras de tiempos pasados, pero esto no quiere decir que desatienda los presentes, como lo atestiguan las reseñas publicadas, que son todas de libros muy recientes.

Y sin embargo, con el fin de darle mayor actualidad a la REVISTA IBEROAMERICANA, que aspira a ser un panorama amplio, completo, imparcial e independiente de las letras iberoamericanas de todos los tiempos, iniciamos ahora una nueva serie de publicaciones, con la esperanza de merecer el apoyo de nuestros lectores. Nos referimos a la “Colección Literaria”, que se compondrá de pequeñas antologías de poetas posteriores al modernismo, las cuales se publicarán, unas (Serie A) como parte integrante de la revista, y otras (Serie B) por separado, en cuadernos de esmerada y atrayente presentación.

Las selecciones de la "Colección Literaria” estarán a cargo de críticos competentes, españoles y americanos, e irán todas acompañadas de estudios y de notas biográficas y bibliográficas. Con el tiempo, la “Colección Literaria de la REVISTA IBEROAMERICANA” constituirá una verdadera antología de la poesía contemporánea de América.

La serie A se inicia en este número con 15 Poemas de Porfirio Barba Jacob, el gran lírico colombiano muerto recientemente en la ciudad de México, y a quien queremos así honrar en esta hora de su descanso y ofrecer el tributo de nuestra grande y profunda admiración.

Volumen V

Mayo 1942

Número 9 